\title{
Analisis Manajemen Proyek untuk Sistem Informasi Penjadwalan Perkuliahan di Jurusan Teknik Informatika
}

\author{
Dewi Mustari, \\ Staf Pengajar Teknik Informatika Universitas Indraprasta PGRI, Jakarta \\ mustaridewi@yahoo.com
}

\begin{abstract}
Abstrak- Universitas X merupakan institusi pendidikan yang menitik beratkan pada pendidikan keguguruan, tapi beberapa tahun ini sudah dibuka Jurusan Teknik Informatika yang menekankan pada penguasaan computer pada mahasiswanya. Penjadwalan menentukan pelaksanaan untuk setiap kegiatan perkuliahan baik matakuliah, ruang, kelas, dosen dan lain-lain. Dalam pelaksanaan pengajarannya teknik informatika membagi mahasiswanya ke dalam beberapa kelas, karena banyaknya mahasiswa. Begitu pula dengan pengajarnya yaitu dosen dibagi dalam beberapa kelompok yaitu dosen tetap satu, dan dosen tetap dua. Karena ruangan kelas sangat terbatas, maka penempatan ruangan pun diatur sedemikian rupa. Oleh karna itu, untuk meningkatkan kualitas pembelajaran supaya perkuliahan bisa berjalan dengan baik tentunya harus didukung oleh teknologi informasi yang mengatur penjadwalan perkuliahan. Tentunya sebelum membuat aplikasi penjadwalan perkuliahan diperlukan analisis manajemen proyek untuk membuat sistem informasi penjadwalan perkuliahan khususnya di Jurusan Teknik Informatika.
\end{abstract}

Kata Kunci: Manajemen Proyek, Penjadwalan, Teknologi Informasi

\section{PENDAHULUAN}

Universitas $\mathrm{X}$ merupakan institusi pendidkan yang menitik beratkan pada pendidikan keguguruan, tapi beberapa tahun ini sudah dibuka Jurusan Teknik Informatika yang menekankan pada penguasaan computer pada mahasiswanya. Penjadwalan menentukan pelaksanaan untuk setiap kegiatan perkuliahan baik matakuliah, ruang, kelas, dosen dan lain-lain. Penjadwalan merupakan pembagian waktu agar dalam pengerjaannya lebih efisien dan teratur. Sedangkan penjadwalan yang ada saat ini masih memiliki banyak kendala yang dihadapi di mulai dari sering terjadinya tabrakan jadwal perkuliahan yang dikarenakan oleh terbatasnya ruangan yang ada. Untuk mengatur semua kegiatan di Teknik Informatika seperti jadwal kuliah, dosen, ruangan, kelas dan lain-lain, maka harus dibuat aplikasi sistem informasi penjadwalan Jurusan Teknik Informatika untuk membantu dalam proses penjadwalan perkuliahan. Masalah yang dihadapi saat ini adalah:

- Sering terjadi tabrakan antara jadwal yang satu dengan yang lainnya,

- Data yang berhubungan denga penjadwalan perkuliahan memiliki database, namun hanya di simpan dalam fale excel,

- Penjadwalan secara manual membutuhkan waktu yang lama, sehingga kurang efisien dan efektif,

- $\quad$ Seiring dengan perkembangan teknologi yang tinggi diharapkan Jurusan Teknik Informatika dapat memiliki aplikasi system informasi penjadwalan yang akan membantu dalam proses penjadwalan.

Jika proyek pembuatan aplikasi penjadwalan telah selesai dan diimplementasikan, maka manfaat yang dapat dirasakan adalah:

- Mengurangi terjadinya tabrakan antar jadwal,

- Data yang berhubungan dengan penjadwalan akan tersimpan lebih aman dalam sebuah database dan lebih mudah dalam penggunaannya,

- Akan lebih efisien dan efektif dalam proses penjadwal perkuliah tanpa harus memakan waktu yang lama,

- Implementasi dalam pemanfaatan teknologi informasi khususnya untuk penjadwalan perkuliahan.

Berbagai cara akan dilakukan dan analisis yang baik agar pemanfaatan teknologi dapat dimanfaatkan dan juga menekan biaya yang harus dikeluarkan. Karyawan yang kami rekomendasikan dalam proyek ini harus bisa menjaga integrasi data dan melatih user supaya dapat menggunakan aplikasi yang dibuat. Aplikasi sistem informasi penjadwalan ini akan lebih meningkatkan kinerja dalam pembuatan jadwal dan pengolahan data penjadwalan. Analisis manajemen proyek ini akan berjalan sesuai dengan rencana dan tujuan, karena Universitas $\mathrm{X}$ akan menggunakan teknologi ini untuk meningkatkan kinerja karyawan bagian penjadwalan. 
Kenapa proyek pembuatan aplikasi ini harus dibuat, jawabannya adalah untuk meningkatkan kinerja petugas penjadwalan maka diperlukan aplikasi yang dapat menunjang pekerjaannya tersebut. Dan dengan adanya aplikasi ini dapat mengurangi terjadinya kesalahan dalam pembuatan jadwal perkuliahan, jadi aplikasi ini sangat penting untuk proses belajar mengajar. Karena proses belajar mengajar ini adalah hal yang sangat penting pada sebuah perguruan tinggi. Dan apabila aplikasi penjadwalan perkuliahan ini tidak dibuat, tentunya akan menimbulkan masalah dikemudian hari apalagi dengan mahasiswa yang banyak tetapi dengan ruangan yang terbatas akan membuat petugas penjadwalan kesulitan dalam membuat jadwal perkuliahan dan juga dalam mengolah data penjadwalan. Oleh karena itu migrasi sistem informasi penjadwalan ini sangat penting, untuk menunjang kinerja karyawan bagian penjadwalan.

Estimasi awal untuk melakukan perubahan ini adalah

- $10 \%$ pembelian computer untuk bagian penjadawalan dalam 1 bulan pertama.

- $60 \%$ pembuatan aplikasi sistem informasi penjadwalan.

- $20 \%$ pengurangan sumber daya, kertas dan tenaga penjadwalan.

- $10 \%$ penurunan jumlah waktu untuk membuat jadwal perkuliahan dan pengolahan komponen jadwal.

\section{LANDASAN TEORI}

Manajemen proyek merupakan kegiatan merencanakan, mengorganisasikan, mengarahkan dan mengendalikan sumberdaya organisasi perusahaan untuk mencapai tujuan dalam waktu tertentu dengan sumber daya tertentu ${ }^{[1]}$. Setiap proyek mempunyai batasan yang berbeda terhadap ruang lingkup, waktu, biaya, yang biasanya disebut sebagai triple constraint (Tiga Kendala). Setiap proyek manajer harus memperhatikan hal penting dalam manajemen proyek. Pertama, ruang lingkup (scope): Apa yang ingin dicapai dalam proyek? Produk atau layanan apa yang pelanggan harapkan dari proyek tersebut? Kedua, waktu (time): Berapa lama waktu yang dibutuhkan untuk menyelesaikan proyek? Bagaimana jadwal kegiatan proyek akan dilaksanakan? Ketiga, biaya (cost): Berapa biaya yang dibutuhkan untuk dapat menyelesaikan proyek?.

Sommervilee [2] menjelaskan secara khusus dalam proyek-proyek IT, seorang manajer proyek IT harus mampu melihat tingkat kesulitan dan kompleksitas proyek IT yang memerlukan perlakuan khusus, yaitu:

- Invisibility (kekasatan)

- Complexity (kompleksitas)

\section{- $\quad$ Flexibility (fleksibilitas)}

Hal ini mengacu pada kenyataan bahwa proyek IT dan keberadaan proyek IT adalah sebagai sarana pendukung bagi komponen lain dalam suatu lingkungan kerja. Dengan demikian proyek IT dapat dikatakan memiliki derajat perubahan yang tinggi (high degree of change). Contoh: pembangunan jaringan komputer di suatu kantor tidak menyebabkan aktivitas di kantor tersebut menjadi mati. Manajemen proyek perangkat lunak merupakan bagian yang penting dalam pembanguan perangkat lunak [3]. Menurut [4], pendukung sistem manajemen proyek adalah waktu, biaya, kualitas, resiko, dan cakupan proyek itu sendiri. Manajemen proyek perangkat lunak diperlukan karena pengembangan proyek perangkat lunak harus selalu tunduk pada batasan anggaran dan jadwal yang telah ditetapkan oleh oraganisasi perangakat lunak. Perangkat lunak merupakan produk yang tidak berwujud (Intangible) sehingga tidak ada standarisasi yang mengatur proses pengembangannya. Aktivitas dalam manajemen proyek perangkat lunak secara garis besar sama dengan aktivitas manajemen pada umumnya.

\section{METODE PENELITIAN}

Metode yang digunakan dalam penelitian ini adalah studi pustaka dari berbagai kasus dalam jurnal atau artikel yang membahas mengenai masalah pelaksanaan manajemen proyek perangkat lunak yang sesuai dengan jadwal dan biaya yang ditetapkan sehingga mengahasilkan analisis deskriptif ${ }^{[5]}$. Dan pendekatan pada penelitian ini adalah pendekatam secara general empiris berdasarkan pengalaman dan teori-teori yang berkaitan dengan manajemen proyek khususnya pada proyek perangkat lunak

\section{PEMBAHASAN}

\section{A. Problem Definision}

1) Problem Statement

Sistem informasi penjadwalan yang ada di Jurusan Teknik Informatika yang sedang berjalan saat ini yaitu masih dilakukan secara manual. Penjadwalan dilakukan dengan mencatat semua data yang berkaitan dengan penjadwalan yang dibutuhkan untuk proses pembuatan jadwal. Seiring berjalannya waktu dan teknologi yang semakin tinggi maka Jurusan Teknik Informatika harus mengganti sistem informasi penjadwalan yang biasanya dibuat dengan manual, akan dimigrasi ke sistem informasi penjadwalan berbasis aplikasi. Hal ini di sesuaikan dengan meningkatnya mahasiswa yang masuk terutama dijurusan teknik informatika, sehingga diperlukan sistem informasi penjadwalan yang bisa menangani semua penjadwalan dijurusan teknik informatika. Bisa 
dibayangkan jika mahasiswa yang masuk sangat banyak maka pastinya kelas akan bertambah sehingga kalau penjadwalan perkuliahan masih dilakukan secara manual pasti karyawan yang terkait dengan penjadwalan membutuhkan waktu yang ekstra untuk mengerjakannya.

2) Organization Impact

Pembangunan aplikasi sistem informasi penjadwalan tentunya akan membawa effect pada Jurusan Teknik Informatika di Universitas X. Berikut ini penjelasan secara detail mengenai organisasi, tools, process, serta peran dan tanggung jawab sebagai akibat dari perubahan atau migrasi sistem informasi penjadwalan.

a) Tools

Dalam implementasinya tentunya dibutuhkan penyesuaian antara metode yang digunakan (Manual) pada metode yang baru yaitu yang lebih canggih sesuai dengan perkembangan IT, dibutuhkan peralatan yang mendukung sesuai dengan spesifikasinya

b) Processes

Dengan aplikasi sistem informasi penjadwalan ini akan dapat dirasakan perbedaannya dengan metode sistem konvensional atau manual, sistem yang baru akan lebih baik yaitu dapat mengefisensikan waktu kerja karyawan dan juga waktu yang dibutuhkan untuk menyusun jadwal tidak lagi lama tetapi cukup beberapa menit untk menyelesaikannya.

c) Role dan Responsibility (Peran dan Tanggung Jawab)

Proyek aplikasi sistem informasi penjadwalan ini akanmemberikan kemudahan bagi penggunannya sehingga pada pembuatan jadwal akan lebih efisien dan effective. Hingga petugas dapat menjalankan tugasnya dengan sebaikbaiknya tanpa memerlukan waktu yang lama.

d) Hardware and Software

Tentunya untuk software, Jurusan Tekni Informatika harus membeli lisensi dari software yang digunakan, dan juga hardware yang digunakan disesuaikan dengan kebutuhan softwarenya.

3) Technology Migration

Data-data yang dibutuhkan untuk membuat penjadwalan dari metode konvensional akandipindahkan atau dimigrasi ke aplikasi sistem informasi yang baru, tahapannya telah dikembangkan untuk meminimalkan segala kendala dalam menjalankan kegiatan. Berikut tahapan secara detail:

- Tahap 1: Software dan Hardware dibeli dan sistem informasi penjadwalan jurusan teknik informatika berbasis aplikasi dan akan di uji oleh team pengembang perangkat lunak yang bersangkutan.

- Tahapan 2: Team IT akan memepersiapkan prototype aplikasi sementara untuk melakukan pengujian di Jurusan teknik informatika yang akan digunakan untuk operasi pembuatan jadwal seperti penginputan data penjadwalan.

- Tahapan 3: Aplikasi yang telah dibuat akan dievaluasi dan di implementasikan, apakah aplikasi tersebut telah sesuai dengan yang diharapkan.

- Tahapan 4: Petugas penjadwalan akan menerima pelatihan dari Team pengembang aplikasi.

- Tahapan 5: Penggunaan aplikasi sistem informasi penjadwalan akan di monitoring oleh Team pengembang selama kurun waktu yang telah disepakati.

\section{B. Project Overview}

1) Project Description

Bertujuan untuk mencari keunggulan sistem informasi penjadwalan secara konvensional, yang mungkin dapat digunakan kembali pada sistem yang akan dibangun. Analisis ini dilakukan untuk mencari keunggulan sistem agar dapat dipertahankan. Setalah mendapatkan keunggulan dari sistem yang sebelumnya tentun akan diterapkan pada aplikasi yang baru sehingga sistem yang baru benar-benar sistem yang memiliki keunggulan sehingga bisa bejalan dengan baik.

2) Goals and Objectives

Tabel 1 Business Goal / Objective

\begin{tabular}{|l|l|}
\hline \multicolumn{1}{|c|}{$\begin{array}{c}\text { Business } \\
\text { Goal/Objective }\end{array}$} & \multicolumn{2}{|c|}{ Description } \\
\hline $\begin{array}{l}\text { Penjadwalan dan } \\
\text { akurat }\end{array}$ & $\begin{array}{l}\text { Aplikasi sistem informasi } \\
\text { penjadwalan akan lebih } \\
\text { menghemat waktu pengerjaan } \\
\text { pembuatan jadwal } \\
\text { perkuliahan dan juga } \\
\text { pelaporan yang akurat } \\
\text { mengenai jadwal perkuliahan } \\
\text { dan data- data penjadwalan } \\
\text { yang mendukung. }\end{array}$ \\
\hline $\begin{array}{l}\text { Peningkatan } \\
\text { efisiensi kerja }\end{array}$ & $\begin{array}{l}\text { Dengan adanya aplikasi } \\
\text { sistem informasi penjadwalan } \\
\text { akan lebih meningkatkan } \\
\text { efisensi waktu bekerja } \\
\text { petugas, karena untuk } \\
\text { melakukan penjadwalan tidak } \\
\text { perlu lagi dibutuhkan waktu } \\
\text { yang lama. }\end{array}$ \\
\hline Penggunaan SDM & $\begin{array}{l}\text { Dengan aplikasi sistem } \\
\text { informasi penjadwalan } \\
\text { tentunya akan membutuhkan } \\
\text { SDM yang bisa menggunakan } \\
\text { aplikasi tersebut }\end{array}$ \\
\hline
\end{tabular}




\begin{tabular}{|l|l|}
\hline Penggunaan Biaya & $\begin{array}{l}\text { Dengan adanya aplikasi baru } \\
\text { tentunya akan mengurangi } \\
\text { biaya untuk membayar } \\
\text { petugas penjadwalan karena } \\
\text { harus lembur dan juga } \\
\text { mengurangi biaya untuk } \\
\text { pembelian kertas. }\end{array}$ \\
\hline
\end{tabular}

3) Project Performance

\begin{tabular}{|c|c|}
\hline \multicolumn{2}{|c|}{ Tabel 2 Project Performance } \\
\hline $\begin{array}{c}\text { Key } \\
\text { Resource/Proce } \\
\text { ss/Service }\end{array}$ & Performance Measurement \\
\hline Pelaporan & $\begin{array}{l}\text { Sistem informasi penjadwalan } \\
\text { berbasis aplikasi akan } \\
\text { memberikan pelaporan selama } \\
\text { satu semester (6 bulan) sesuai } \\
\text { dengan pergantian semester } \\
\text { maka jadwal akan berubah } \\
\text { persemester sehingga harus } \\
\text { mengurangi kesalahan dalam } \\
\text { hal pelaporan mengenai } \\
\text { penjadwalan perkuliahan, }\end{array}$ \\
\hline $\begin{array}{l}\text { Penjadwalan } \\
\text { perkuliahan dan } \\
\text { entri data - data } \\
\text { jadwal }\end{array}$ & \begin{tabular}{lrr} 
Petugas yang & \multicolumn{2}{c}{ bersangkuatan } \\
dapat membuat jadwal & sesuai \\
dengan ketentuan & dan \\
menginput data- & data \\
penjadwalan yang & belum \\
tersedia pada database. & \\
\end{tabular} \\
\hline $\begin{array}{l}\text { Software dan } \\
\text { perawatan } \\
\text { sistem }\end{array}$ & $\begin{array}{l}\text { Sistem yang baru membutuhkan } \\
\text { perawatan, perawatan dilakukan } \\
\text { dengan memonitor aplikasi } \\
\text { penjadwalan. }\end{array}$ \\
\hline SDM & $\begin{array}{l}\text { Dengan adanya sistem yang } \\
\text { baru tentunya sumber daya } \\
\text { manusianya pun harus sesuai } \\
\text { dengan kebutuhan sistem yaitu } \\
\text { yang mengerti mengenai sistem } \\
\text { informasi, sehingga dapat } \\
\text { menggunakan aplikasi dengan } \\
\text { baik. }\end{array}$ \\
\hline
\end{tabular}

\section{4) Project assumptions}

Asumsi berikut berlaku untuk sistem informasi penjadwalan jurusan teknik informatika. Sebagai perencanaan project sistem informasi penjadwalan dimulai dan asumsi lebih banyak di identifikasi, maka akan ditambahkan sesuai dengan kebutuhan:

- Petugas yang bertanggung jawab pada pembuatan jadwal perkuliahan tentunya akan diberikan pengarahan atau training untuk sistem penjadwalan yang baru.

- Merencanakan waktu yang tepat untuk pelaksanaan pembuatan aplikasi yang baru.

- Penyediaan peralatan yang dibutuhkan untuk sistem aplikasi penjadwalan yang baru baik itu perangkat keras ataupun perangkat lunak.
- Bagian yang berhubungan dengan sistem penjadwalan tentunya akan ikut membantu dalam pelaksanaan migrasi ke sistem baru.

- Tentunya project ini didukung penuh oleh Universitas X.

\section{5) Project constraints}

Tentunya dalam migrasi suatu sistem akan mengalami kendala - kendala yang akan dihadapi diantaranya:

- Diperlukannya pengenalan sistem yang baru kepada petugas yang bersangkutan.

- Keterbatasan dalam mencari Sumber Daya IT yang dapat mengimigrasi secara detail sistem informasi penjadwalan.

- Keterbatasan dukungan pada saat implementasi aplikasi penjadwalan.

6) Major Project Milestones.

Tabel 3 Perencanaan Pengerjaan Projek Sistem Informasi Penjadwalan

\begin{tabular}{|c|c|c|c|c|c|c|c|}
\hline \multirow{2}{*}{ 10 Trasklane } & \multirow{2}{*}{ Sath } & \multirow{2}{*}{ Finish } & \multirow{2}{*}{ Dradon - } & lag 2016 & dandrot & w20/6 & Ag9/6 \\
\hline & & & & \multicolumn{4}{|c|}{ 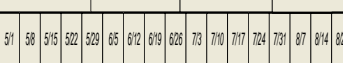 } \\
\hline 1 Penenaran Anal & 592016 & 5162016 & 60 & $\square$ & & & \\
\hline 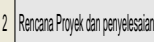 & 5162016 & 63016 & 150 & 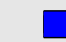 & & & \\
\hline 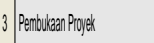 & 662016 & 60202016 & 100 & & $\square$ & & \\
\hline 4 Tahap 1 complete & 602016 & 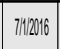 & 100 & & & & \\
\hline 5 Talap 2 complete & 742016 & 7152016 & 100 & & & & \\
\hline 6 Ttalap 3complete & 7140216 & 72201016 & 100 & & & & \\
\hline 7 Tahap 4 complete & 17272016 & 850016 & 80 & & & & \\
\hline 8 | Talaps ommede & 882016 & 8152016 & od & & & & $\square$ \\
\hline 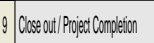 & 8182016 & 822016 & \$ & & & & च \\
\hline
\end{tabular}

C. Strategic Alignment (Kesejajaran Strategi)

Proyek pembuatan aplikasi sistem informasi penjadwalan merupakan bagian dari rencana strategi Universitas $X$. Dengan langsung mendukung rencana-rencana strategis Universitas $\mathrm{X}$, tentunya proyek sistem informasi penjadwalan ini akan meningkatkan kinerja dan juga layanan sistem informasi penjadwalan bagi dosen dan mahasiswa.

Tabel 4 Strategic Alignment

\begin{tabular}{|l|l|l|}
\hline \multicolumn{1}{|c|}{ Plan } & \multicolumn{1}{|c|}{$\begin{array}{c}\text { Goal/Objectiv } \\
\text { es }\end{array}$} & \multicolumn{2}{|c|}{$\begin{array}{c}\text { Relationship to } \\
\text { Project }\end{array}$} \\
\hline 2017 & Dengan & Aplikasi baru \\
Universitas & membuat & tentunya akan \\
X & aplikasi sistem & meningkatkan \\
perencanaan & informasi & kualitas kerja \\
Penjadwalan & penjadwalan & bagian \\
perkuliahan & yaitu migrasi & penjadwalan dan \\
& dari manual ke & juga efisiensi \\
\hline
\end{tabular}




\begin{tabular}{|c|c|c|}
\hline & $\begin{array}{l}\text { berbasis } \\
\text { aplikasi }\end{array}$ & $\begin{array}{l}\text { waktu yang } \\
\text { dibutuhkan untuk } \\
\text { mengolah jadwal } \\
\text { perkuliahan. }\end{array}$ \\
\hline $\begin{array}{l}2017 \\
\text { Universitas } \\
\mathrm{X} \\
\text { Melakukan } \\
\text { pengelolaan } \\
\text { informasi }\end{array}$ & $\begin{array}{l}\text { Memanfaatkan } \\
\text { teknologi yang } \\
\text { baru untuk } \\
\text { mendukung } \\
\text { visi dan misi } \\
\text { Universitas X }\end{array}$ & $\begin{array}{l}\text { Teknologi baru } \\
\text { yaitu aplikasi } \\
\text { penjadwalan ini } \\
\text { akan mendukung, } \\
\text { terutama dalam } \\
\text { proses belajar } \\
\text { mengajar agar } \\
\text { tidak terjadi } \\
\text { tabrakan jadwal. }\end{array}$ \\
\hline $\begin{array}{l}2017 \\
\text { Universitas } \\
X \\
\text { meningkatk } \\
\text { an kualitas } \\
\text { pendidikan } \\
\text { internal }\end{array}$ & $\begin{array}{l}\text { Meningkatkan } \\
\text { SDM yaitu } \\
\text { karyawan dan } \\
\text { dosen }\end{array}$ & $\begin{array}{lr}\text { Proyek } & \text { ini } \\
\text { bertujuan agar } & \text { dan } \\
\text { dosen } & \text { dapat } \\
\text { karyawan } & \text { danggunakan } \\
\text { aplikasi yang } \\
\text { baru dengan } \\
\text { meningkatkan } \\
\text { kualitas } \\
\text { pendidikan } \\
\text { khususnya untuk } \\
\text { karyawan yang } \\
\text { bertugas pada } \\
\text { bagian } \\
\text { penjadwalan }\end{array}$ \\
\hline
\end{tabular}

\section{Cost Benefit Analysis}

Merupakan penjabaran pembiayaan yang terkait dengan migrasi sistem informasi penjadwalan jurusan teknik informatika.

Tabel 5 Cost Benafit Analysis

\begin{tabular}{|l|l|l|c|}
\hline Action & $\begin{array}{c}\text { Action } \\
\text { Type }\end{array}$ & $\begin{array}{c}\text { Firt year } \\
\text { costs } \\
\text { (indicated } \\
\text { anticipate } \\
\text { d saving) }\end{array}$ \\
\hline $\begin{array}{l}\text { Pembelia } \\
\text { n } \\
\text { peralatan } \\
\text { kompute } \\
\text { r }\end{array}$ & Cost & $\begin{array}{l}\text { Dana untuk } \\
\text { pembelian } \\
\text { computer baru }\end{array}$ & 10.000 .000 \\
\hline $\begin{array}{l}\text { Pemasan } \\
\text { gan } \\
\text { software } \\
\text { dan } \\
\text { pengujic } \\
\text { obaan }\end{array}$ & Cost & $\begin{array}{l}\text { Dana untuk } \\
\text { persiapan } \\
\text { aplikasi } \\
\text { perangkat } \\
\text { lunak dan } \\
\text { pengujicobaan } \\
\text { selama } \\
\text { beberapa } \\
\text { waktu }\end{array}$ & 8.000 .000 \\
\hline $\begin{array}{l}\text { Pemangk } \\
\text { asan alat } \\
\text { administ } \\
\text { rasi lama }\end{array}$ & Saving & $\begin{array}{l}\text { Pengurangan } \\
\text { pemakaian } \\
\text { kertas, buku } \\
\text { dan alat-alat } \\
\text { tulis lainya }\end{array}$ & 15.000 .000 \\
\hline
\end{tabular}

\begin{tabular}{|l|l|l|l|}
\hline $\begin{array}{l}\text { Efisiensi } \\
\text { kerja } \\
\text { petugas } \\
\text { penjadw } \\
\text { alan }\end{array}$ & Saving & $\begin{array}{l}\text { Pengurangan } \\
\text { petugas dan } \\
\text { jam lembur } \\
\text { yang biasanya } \\
\text { dilakukan } \\
\text { pada saat } \\
\text { membuat } \\
\text { jadwal }\end{array}$ & 10.000 .000 \\
\hline $\begin{array}{l}\text { Pemeliha } \\
\text { raan } \\
\text { system } \\
\text { selama } \\
\text { satu } \\
\text { tahun }\end{array}$ & Cost & $\begin{array}{l}\text { Dengan } \\
\text { mengurangi } \\
\text { alat-alat } \\
\text { lainnya maka } \\
\text { dapat } \\
\text { menghemat } \\
\text { pengadaan } \\
\text { barang dan } \\
\text { perawatan }\end{array}$ & 10.000 .000 \\
& & & \\
\hline $\begin{array}{l}\text { Penghem } \\
\text { atan } \\
\text { dana }\end{array}$ & & & 15.000 .000 \\
\hline
\end{tabular}

Berdasarkan analisis dari tabel diatas maka dapat disimpulkan dengan adanya migrasi system informasi penjadwalan berbasis aplikasi dapat menghemat uang sebanyak Rp.15.000.000 per enam bulannya. Ini merupakan sesuatu perbaikan yang bisa dibilang sukses sesuai dengan yang diharapkan, yang bisa menekan biaya se maksimal mungkin untuk biaya operasional.

\section{E. Alternative Analysis}

Pilihan alternative yang telah dipertimbangkan sebelumnya untuk mengatasi masalah penjadwalan perkuliahan dengan menggunakan metode konvensional. Alternative ini tidak dipilih untuk sejumlah alasan juga dijelaskan dibawah ini:

Tabel 6 Alternative Analyisis

\begin{tabular}{|c|c|}
\hline $\begin{array}{l}\text { No Project } \\
\text { (Status Quo) }\end{array}$ & $\begin{array}{c}\text { Alasan karena tidak memilih } \\
\text { alternative }\end{array}$ \\
\hline $\begin{array}{l}\text { Menjaga sistem } \\
\text { konvensional }\end{array}$ & $\begin{array}{l}\text { a. } \text { Memerlukan penambahan } \\
\text { dana saat-saat tertentu } \\
\text { b. Banyak terjadinya kesalahan } \\
\text { terutama pada saat } \\
\text { penjadwalan bisa } \\
\text { mengakibatkan terjadinya } \\
\text { tabrakan antar jadwal. } \\
\text { c. Berkas-berkas yang } \\
\text { digunakan kemungkinan } \\
\text { bisa hilang atau tertumpuk } \\
\text { dengan yang lain sehingga } \\
\text { menyulitkan dalam } \\
\text { pencarian } \\
\text { d. Pekerjaan membutuhkan } \\
\text { waktu yang cukup lama. }\end{array}$ \\
\hline $\begin{array}{c}\text { Pilihan } \\
\text { alternative }\end{array}$ & $\begin{array}{c}\text { Alasan karena tidak memilih } \\
\text { alternative }\end{array}$ \\
\hline $\begin{array}{l}\text { Penggunaan } \\
\text { Sistem } \\
\text { Outsoursching }\end{array}$ & $\begin{array}{l}\text { a. Harganya yang mahal } \\
\text { b. Tidak memiliki mitra kerja } \\
\text { c. Banyak dosen yang bisa }\end{array}$ \\
\hline
\end{tabular}




\begin{tabular}{|c|l|}
\hline & \multicolumn{1}{|c|}{$\begin{array}{l}\text { membuat aplikasi } \\
\text { penjadwalan perkulihan }\end{array}$} \\
\hline $\begin{array}{c}\text { Pilihan } \\
\text { alternative }\end{array}$ & $\begin{array}{c}\text { Alasan karena tidak memilih } \\
\text { alternative }\end{array}$ \\
\hline $\begin{array}{l}\text { Pengembangan } \\
\text { sistem internal }\end{array}$ & $\begin{array}{l}\text { Pada dasarnya mirip dengan } \\
\text { metode konvensional }\end{array}$ \\
\hline
\end{tabular}

\section{KESIMPULAN}

Dari penelitian yang telah diuraikan, maka didapatlah kesimpulan mengenai pembahasan dari analisis manajemen proyek pembuatan sistem informasi penjadwalan perkuliahan yaitu:

- Dengan melakukan analisis manajemen proyek untuk sistem informasi penjadwalan perkuliahan, tentunya akan mendapatkan gambaran apa saja yang dibutuhkan untuk membuat sistem tersebut,

- Dengan melakukan analisis manajemen proyek untuk sistem informasi, tentunya dapat menentukan jadwal pembuatan aplikasi tersebut dan target yang harus di selesaikan sampai aplikasi sistem informasi penjadwalan tersebut selesai,

- Dengan melakukan nanalisis manajemen projek, tentunya dapat menentunya biaya yang harus dikeluarkan,

- Dari analisis manajemen proyek yang dilakukan selain dapat gambaran mengenai aplikasi yang akan dibuat namun juga mendapat analisis alternative yang bisa dipertahankan.

\section{DAFTAR PUSTAKA}

[1] Santoso, Budi. (2003). Manajemen Proyek. Jakarta: Guna Widya.

[2] I. Sommerville. (2011). Software Engineering Version 9.

[3] U. Proboyekti, Manajemen Proyek PerangkatLunak.http://lecturer.ukdw.ac.id/othi e/projectmanage.pdf. Diakses Mei 2015.

[4] H. Fransiska, R.F. Pudiyanto, Suwarnold, "Analisis dan Perancangan Aplikasi Manajemen Proyek Khususnya Permintaan Perubahan (Chage Request) Berbasis Web untuk Devisi TI Pada PT. WOM FINANCE”, Skripsi Universitas Bina Nusantara, 2015.

[5] Alusyanti P dan Dewi M. (2013). Analisis Manajemen Proyek Perangkat Lunak Sistem Informasi Akuntasi Pada Biro Sistem Informasi PT.X. 